\title{
WHY EMPLOYEES SHARE THEIR KNOWLEDGE
}

\author{
Jana Matošková
}

\section{Introduction}

Motivation research has a long history of considering employee motives and needs, and it is still popular. To find the reason, it is not necessary to look for a long time. Numerous studies have shown that employees could be the most valuable asset that organizations have. Employees, with their knowledge, skills, abilities, and work attitudes, influence how efficiently resources and means are used. Kazdová (2012) says that the employee who is motivated speaks about the firm positively, sees his/her future in the firm, and makes an extra effort which leads to the improvement of organizational outputs.

According to Swift, Balkin, and Matusik (2010), employee motivation influences knowledge sharing in the organization, among other things. If the employee is motivated, he/ she is more willing to share knowledge (Hau, Kim, Lee, \& Kim, 2013). And just knowledge sharing is a phenomenon which comes to the fore. A lot of studies have proved that knowledge sharing is useful (e.g. Urbancová, 2012). Sharing knowledge not only reduces the risk of losing unique knowledge if a certain employee leaves the organization, but it also contributes to higher productivity and to higher quality of an organization's performance (Law \& Ngai, 2008; Tuan, 2012; Yen-Ku Kuo, Tsung-Hsien Kuo, \& Li-An Ho, 2014), to better problem-solving (Yen-Ku Kuo et al., 2014), and to reducing costs (Peet, 2012). It also supports organizational innovativeness (Li-An \& Kuo, 2013) and can lead to better understanding of customers and other stakeholders. In sum, it is vital to exploit core competencies and to achieve a sustained competitive advantage (Anwar, 2017). That is why plenty of organizations start to ask themselves: How to support knowledge sharing?

To the organization that wishes to facilitate knowledge sharing, it seems crucial to understand employee motives for it. However, not many studies deal with this topic. And if they do, they take motivation as a general construct. Nevertheless, as some studies (e.g. Barbuto \& Scholl, 1998; Gottschalg \& Zollo, 2007) indicate, motivation is a rather multidimensional construct. Therefore, the goal of this study is to examine employee motivation for knowledge sharing in more detail and find out which kind of motivation is essential to knowledge sharing. The basic research questions are: Why do employees share their knowledge? Is it because of their intrinsic or extrinsic motivation? And if intrinsic motivation matters, then what kind? This study contributes to a better understanding of the phenomenon of knowledge sharing between individuals in organizations.

The paper is organized as follows: First, theoretical framing is introduced, then the methods used are described. After that, results and discussion are presented, followed by conclusions.

\section{Theoretical Framing}

This chapter provides a brief overview of the key concepts and literature findings related to the topic. It discusses terms like knowledge, knowledge sharing, knowledge management, and motivation. It begins with the concept of "knowledge".

For Davenport and Prusak (1998 as cited in Ipe, 2003), knowledge refers to a fluid mix of framed experience, values, contextual information, and expert insights that provides a framework for evaluating and incorporating new experiences and information. Given this, at least a part of one's knowledge is based upon judgement and experience (Ardichvili, Page, \& Wentling, 2003; Fong, Ooi, Tan, Lee, \& Chong, 2011; Ipe, 2003), which is one of the reasons why numerous studies discuss that knowledge can be one of the sources of organizational 
competitiveness. Additionally, to exploit this source, it is in the interest of an organization that employees do not keep their knowledge to themselves but that they share it with other members of the organization.

Knowledge sharing refers to the provision of task information and know-how to help others and to collaborate with others to solve problems, develop ideas, or implement policies or procedures (Wang \& Noe, 2010 as cited in Seba, Rowley, \& Lambert, 2012). This study contributes to the limited research base on knowledge sharing in public sector organisations, specifically police forces, and organisations in the Middle East through a case study investigation into the factors that affect knowledge sharing in the Dubai Police Force. A questionnaire-based survey was conducted with staff in key departments in the Dubai Police Force. Informed by the literature and by interviews conducted in a previous phase, the core of the questionnaire was a bank of Likert-style questions covering the dependent variables intention to knowledge share, and attitude towards knowledge sharing, and the independent variables, trust, organisational structure, leadership, reward, time, and information technology. Data was analysed using structured equation modelling, in order to test the measurement model using confirmatory factor analysis, and to test the structural model. The structural model suggests a strong relationship between attitude to knowledge sharing, and intention to share knowledge. Hypotheses regarding the influence of leadership, trust, organisational structure, time, and information technology on attitude to knowledge sharing were upheld. Rewards did not to influence attitude to knowledge sharing. Recommendations are offered for practice and further research. This provision means basically what Ipe (2003) describes as the act of making knowledge available to others within the organization by converting it into a form that can be understood, absorbed, and used by other individuals. According to Haas and Hansen (2007), knowledge sharing could be direct (addressed to a given recipient, which requires contact between the provider and receiver of the knowledge - at meetings, by phone, through e-mail) or indirect (passed along through written documents or databases and not directed to a specific person, meaning the receiver of the document does not have to contact the provider directly but can use the document as a standalone resource). Regarding knowledge sharing, Husted and Michailova (2002) argued that it is not a new phenomenon, because employees have always asked their colleagues for advice. What is new is systematizing knowledge sharing activities, as a result of the realization that relying on self-emerging knowledge sharing is ineffective. The causes of ineffectiveness are individual preferences, such as one's preference for seeking missing answers in the local environment.

Systematizing knowledge sharing activities belongs to processes in knowledge management (Singh, 2008; Wong, 2005). Unfortunately, knowledge management lacks a generally accepted definition. However, an interesting definition is offered by Liss (1999 as cited in Singh, 2008), who claims that knowledge management is a formal, directed process of determining what information a company has that could benefit others and then devising ways to make it easily available to all concerned. Knowledge management focuses on systematic and innovative methods, practices, and tools for managing the generation, acquisition, exchange, protection, distribution, and utilization of knowledge, intellectual capital, and intangible assets (Montana, 2000 as cited in Lin \& Lee, 2004).

As measurement is the least developed aspect of knowledge management (Bose, 2004), it is difficult to find a generally accepted inventory for the measurement of knowledge sharing. Methods used for this aim which appeared in the literature have been divided into three types by Matošková (2016): 1) hard data measurement, 2) opinion-based surveys which examine such constructs as willingness to share knowledge, knowledge-sharing behaviour and factors which can influence it, or identify potential knowledge holders and potential for mutual knowledge sharing, and 3) combination of hard and soft indicators.

With regard to knowledge sharing, it is essential to understand that knowledge sharing cannot be forced by managers but can only be encouraged and facilitated (Gibbert \& Krause 2002 as cited in Bock, Zmud, Kim, \& Lee, 2005). The main cause is that the key actors who possess the insight necessary for successful knowledge sharing are the knower and the one(s) in need of knowledge (Husted \& Michailova, 2002). Furthermore, it is also worth 
noting that to transfer knowledge which would be completely consistent with the original is usually not possible - everyone forms their own tacit knowledge on the basis of their previous experience, knowledge, skills, and mental models (Matošková et al., 2013). Moreover, knowledge sharing in the organization may be limited as a consequence of the existence of knowledge sharing barriers. Riege (2005) several barriers make it difficult for $\mathrm{KM}$ to achieve the goals and deliver a positive return on investment. This paper provides a detailed review of current $\mathrm{KM}$ and related literatures on a large number of possible knowledgesharing barriers with the purpose of offering a more comprehensive and structured startingpoint for senior managers when auditing their organisation's current knowledge base and knowledge-sharing requirements. This article reviews and discusses over three dozen potential knowledge-sharing barriers, categorising them into three main domains of recently published works: individual/personal, organisational, and technological barriers. The extensive list of knowledge sharing barriers provides a helpful starting point and guideline for senior managers auditing their existing practices with a view to identifying any bottlenecks and improving on the overall effectiveness of knowledge-sharing activities. Managers need to realise, however, that a particular knowledge sharing strategy or specific managerial actions will not suit all companies and that there are differences to be expected between MNCs and SMEs, private, public sector, and not-for-profit organisations. As such, the implementation of knowledge-sharing goals and strategies into an organisation's strategic planning and thinking will vary greatly. Riege (2005) grouped knowledge sharing barriers into three broad types: 1) individual, 2) organizational, and 3) technological. Lack of time to share or fear that sharing may reduce or jeopardise people's job security are good illustrations of individual knowledge sharing barriers. Organizational barriers can be illustrated by lack of leadership and managerial direction and lack of transparent rewards and recognition systems that would motivate people to share more of their knowledge. Classic examples of technological barriers are lack of compatibility between diverse IT systems and processes and reluctance to use IT systems due to lack of familiarity and experience with them.
The key trigger for knowledge sharing is probably motivation (C.-P. Lin, 2007; Sandhu, Jain, \& Ahmad, 2011). Generally, motivation reflects an impulse toward a specific behaviour. Regarding knowledge sharing, as Quigley, Tesluk, Locke, and Bartol (2007) explain, motivation is important for engaging in the effort and time required for this activity and overcoming attitudes toward knowledge hoarding. Similarly, Wong (2005) says if individuals are not motivated, no amount of investment, infrastructure, and technological intervention will make knowledge management activities effective. It is worth adding that the motivation to behave in a certain way is influenced by a) the degree to which the behaviour helps individuals to meet their goals and b) the relevance of each goal to the individual (Gottschalg \& Zollo, 2007).

Several types of motivation were identified in previous studies. Deci and Ryan (2000) deal with so-called intrinsic motivation in depth. They state that intrinsically motivated activities are those that people do naturally and spontaneously when they feel free to follow their inner interests. Furthermore, they mentioned that when extrinsic rewards are introduced for doing an intrinsically interesting activity, people tend to feel controlled by the rewards and feel less like originators of their behaviour and thus display less intrinsic motivation. On the other hand, extrinsic motivation means that people's behaviour is controlled by specific external contingencies and people behave to attain a desired consequence such as tangible rewards or to avoid threatened punishment. An interesting classification of motivation was presented by Gottschalg and Zollo (2007) in relation to organizational commitment. They describe three basic types of motivation extrinsic, hedonic intrinsic, and normative intrinsic. Extrinsic motivation is driven by the goal of obtaining extrinsic work rewards or outcomes, such as money, power, recognition, and so forth. Hedonic intrinsic motivation is driven by the goal of being engaged in enjoyable, self-determined, and competence-enhancing behaviour. Normative intrinsic motivation is driven by the goal of engaging in behaviour that is compliant with norms and values of a social community (a firm). Gottschalg and Zollo (2007) state that the intensity of normative intrinsic motivation depends on the degree to which individuals identify with the quasi-stable 
organizational norms and values. This means that it is connected with so-called organizational commitment. The relationship between commitment to the organization and willingness to share knowledge has been noticed by other authors too (e.g. Hooff \& Ridder, 2004).

A significant question in the case of knowledge sharing is what enhances employee motivation for it. Generally, the motivation for knowledge sharing can be affected by human resource practices (Chen \& Huang, 2009), interpersonal relationships (Chen, Chuang, \& Chen, 2012; Hooff \& Ridder, 2004), organizational culture (Cabrera \& Cabrera, 2005; Donate \& Guadamillas, 2011), or by providing information and communication technologies (Seba et al., 2012). However, different activities which an organization engages in to encourage knowledge sharing can influence different types of motivation.

In relation to intrinsic motivation, three human resource practices are mentioned: a) job design, b) cultivation of organizational culture, and c) recruitment and selection. Job design tactics which increase intrinsic motivation are job variety and autonomy (Foss, Pedersen, Reinholt Fosgaard, \& Stea, 2015). The cultivation of organizational culture means creating a culture that facilitates knowledge sharing. Such a culture is connected with characteristics such as: providing support for experimentation and learning from both failures and successes (Chow, Deng, \& Ho, 2000), sharing and cooperation as behavioural norms (Bock et al., 2005; Quigley et al., 2007), and procedural justice (Bock et al., 2005). In the case of recruitment and selection, it is essential to select a candidate who has the common perception of knowledge sharing (Fong et al., 2011) and a high self-efficacy (Chen et al., 2012; H.-F. Lin, 2007). It is surprising that no studies were found which would take into account that different types of intrinsic motivation exist in relation to knowledge sharing.

Extrinsic motivation can be influenced by such human resource practices as performance management, rewards, and career advancement. However, as was explained earlier, it is supposed that offering extrinsic rewards for a certain behaviour tends to decrease the perceived intrinsic value of the behaviour (Deci, 1975 as cited in Cabrera \& Cabrera, 2005). Nevertheless, Foss et al. (2015) point out that it is deciding what meaning human resource practices have to the recipient, because this will influence its effect. It is desirable that human resource practices emphasize employee competence affirmation rather than control (Cabrera \& Cabrera, 2005; Foss et al., 2015). These facts might be a reason why studies examining effects of rewards on knowledge sharing offer different results. For example, according to the findings of Lin (2007) little empirical research has been conducted examining the different kinds of motivation (extrinsic and intrinsic, expected organizational rewards did not significantly influence employee attitudes and intentions towards knowledge sharing. On the other hand, Cabrera, Collins, and Salgado (2006) found that rewards have a moderate direct effect on knowledge sharing. This study can contribute to discussion about the relationship between extrinsic motivation and knowledge sharing.

To measure motivation for knowledge sharing or attitudes toward it, opinion-based surveys are usually used. For example, Chow, Deng, and Ho (2000) examine the willingness to share knowledge using two scenarios, where participants answer with how a typical employee of their organization would respond in a given situation, and at the same time indicate on a scale of 1 to 9 how likely it is that he/she would share his/her knowledge in such a situation. A more typical inventory was used, for example, by Seba et al. (2012) and Lin and Lee (2004). In their surveys, all constructs were measured using multiple items. Respondents' attitudes and opinions were measured using five-point or seven-point Likert scale questions (ranging from strongly disagree to strongly agree).

\section{Goals and Methods}

This chapter describes and discusses the goals and the methods used in this study. The aim of this study is to explore which kind of employee motivation is essential to knowledge sharing and to examine four hypotheses in relation to this:

H1: There is a positive statistically significant correlation between employee motivation for knowledge sharing and knowledge sharing in the organization.

H2: There is a positive statistically significant correlation between employee hedonic intrinsic motivation for knowledge sharing and knowledge sharing in the organization.

H3: There is a positive statistically significant correlation between employee normative 
intrinsic motivation for knowledge sharing and knowledge sharing in the organization.

H4: There is a positive statistically significant correlation between employee extrinsic motivation for knowledge sharing and knowledge sharing in the organization.

A quantitative research design based on opinion-based questionnaires was applied in the study. It is described in detail in the following subchapter.

\subsection{Participants}

In total, 315 participants from 89 organizations completed the questionnaire focused on knowledge sharing in the organization. Four participants were not from the Czech Republic. However, only 229 participants from nine organizations from the Czech Republic completed the questionnaire aimed at employee motivation for knowledge sharing. Of these, $67 \%$ of respondents were from manufacturing companies, $23 \%$ from construction firms, $9 \%$ from educational organizations, and $1 \%$ from companies who deal with electricity, gas, steam and air condition supply.

For the correlation analysis, only those cases were chosen where it could be guaranteed that both questionnaires were completed by the same participants. This was only the case in six organizations and in the case of 102 participants. Regarding the number of employees, two organizations belonged to small ones, two to middle ones, and two to big ones. The structure of the respondents was as follows: $36 \%$ from manufacturing companies, $41 \%$ from construction firms, $20 \%$ from educational organizations, and $3 \%$ from companies who deal with electricity, gas, steam and air condition supply. Regarding work positions, $22 \%$ respondents were managers, $7 \%$ were $\mathrm{HR}$ employees, $70 \%$ hold other work positions, and 1 participant omitted this question. Additionally, $54 \%$ participants were men. As far as education is concerned, $23 \%$ participants have apprenticeship certificate, $32 \%$ have secondary education, and $45 \%$ have university degrees. Unfortunately, three questionnaires had to be omitted in the calculation of bias corrected and accelerated bootstrap $95 \% \mathrm{Cls}$ for a correlation analysis (see Tab. 3).

\subsection{Measures}

This study measured two constructs knowledge sharing in the organization and employee motivation for knowledge sharing. Both constructs were measured using multiple items.

Knowledge sharing in the organization. This questionnaire measures the perceived intensity of knowledge sharing in the organization, with regard to the intensity of knowledge documentation and work with such knowledge as well as the intensity of social interactions among employees. The inventory used consists of 15 items (see Appendix 1). The items were chosen based on content analysis of the literature and used, for example, the following inventories as inspiration: Bock, Zmud, Kim, and Lee (2005), Zaqout and Abbas (2012), Lin (2007). Two versions of the inventory were distributed - one version was meant for managers and HR employees; the second version was for others. The only difference between the versions was that the items for managers and HR employees contained the phrase "typical employee" whereas the items for others were formulated in "I-form." Participants evaluated the items according to their agreement with the given statement, on a scale from 1 to 5 ( 1 = strongly disagree and $5=$ fully agree). The scale of knowledge sharing used had high reliability, Cronbach's $\alpha=.86$.

Employee motivation for knowledge sharing. This questionnaire finds out which type of employee motivation for knowledge sharing predominates. Similarly to the study of Foss, Pedersen, Reinholt Fosgaard, and Stea (2015), "motivation" does not refer to a general, stable personality trait, but it reflects an impulse toward a specific behaviour (knowledge sharing). The inventory used consisted of 12 items. These two studies were used in its construction: Barbuto and Scholl (1998) and Gottschalg and Zollo (2007). Four items were suggested to be related to hedonic intrinsic motivation, four to normative intrinsic motivation, and four to extrinsic motivation. The exploratory factor analysis of this inventory was a part of this study. Because of the inventory construction, it was supposed that three factors would appear.

\subsection{Procedure}

In the framework of the study, the rules of ethical research were applied and the questionnaires were anonymous. Data collection was based on self-fulfilment, i.e. questions were not read to participants by an interviewer, the fulfilment 
was completely in the participant's charge. Participation in the study was voluntary. The participants were informed that the data was being collected in the framework of a research project and that it would serve for scientific aims.

"Pen and paper" as well as online questionnaires were used. Some organizations were asked firstly to complete the knowledge sharing questionnaire online and then they were offered to continue with the second questionnaire, which was not effective, because the organizations refused to complete the second questionnaire. After this discovery, a "pen and paper" variant with two questionnaires administered separately was tested in three organizations. The idea was that this method would be more comfortable for respondents because they could complete one questionnaire in their free time and then another. However, this procedure was not too successful, because it was not possible to bring together questionnaires completed by the same respondent and therefore these questionnaires could not be used for the correlation analysis. Additionally, it was necessary to rewrite data from the papers into an electronic version, which was more time-consuming. Therefore, finally in six organizations, online subsequent questionnaires were used.

Based on consultations with some organisations, we supposed that the topic would be considered to be sensitive by many firms and the willingness to participate would be low. That was why we did not restrict the choice of companies according to their branch or their size and we tried to attract as many participants as possible. Therefore, many methods were used to contact potential respondents, e.g. sending e-mails to firms from TOP 100 Czech firms and to members of the People Management Forum and the Regional Chamber of Commerce, then sharing information about the survey on social networks Facebook and Linkedln, posting information on Facebook and the web pages of our faculty, cooperation with students and graduates, propagation of the survey at a conference and a workshop, and a PR article in a journal for HR employees. However, the willingness of organizations to cooperate was very low as we supposed in advance. The best method was probably the use of personal contacts, and that is how a closer cooperation with nine organizations was established.

\subsection{Data Analysis}

All data were transformed into an electronic version. Then IBM $®$ SPSS $₫$ Statistics software was used for data analysis. First, a principal axis factor analysis was conducted on employees' motivation for knowledge sharing. Items from the questionnaire aimed at employees' motivation for knowledge sharing which have factor loadings below .40 were excluded from further analysis. An index of motivation was counted for each factor as well as for the total motivation for knowledge sharing. For this aim, the points on the Likert scale were transformed into number scores. The indexes for each factor were counted as quotients from the sum of points gained in items related to the factor to the maximum points which could be gained in these items. The maximum score means a situation where the participant gives a 5 to all statements related to the factor. If the participant left an item blank, this was taken into consideration and the maximum score was adequately reduced. Similarly, the index of the total employees' motivation for knowledge sharing was counted. It follows that the quotients can acquire a value from 0.2 to 1 . After the factor validity of the inventory and its reliability analysis with the use of Cronbach's alpha, basic statistical characteristics of the tests employed in the survey were examined. Additionally, Pearson's correlations were used to examine the defined hypotheses.

\section{Results and Discussion}

This chapter presents and discusses the findings which emerged from the statistical data analysis. First, the inventory of employee motivation is examined. Then the results of correlation analysis between motivation and knowledge sharing are introduced.

A principal axis factor analysis was conducted on the 12 items of employees' motivation for knowledge sharing with oblique rotation (direct oblimin). The Kaiser-MeyerOlkin measure verified the sampling adequacy for the analysis, $\mathrm{KMO}=.87$ ("meritorious" according to Hutcheson and Sofroniou (1999)), and all KMO values for individual items were greater than .64, which is above the acceptable limit of .5 (Field, 2013). An initial analysis was run to obtain eigenvalues for each factor in the data. Three factors had eigenvalues over Kaiser's criterion of 1 and in combination explained $71.53 \%$ of the variance. Tab. 1 shows 


\begin{tabular}{|c|c|c|c|c|}
\hline \multirow[b]{2}{*}{ Item } & & \multicolumn{3}{|c|}{ Rotated Factor Loadings } \\
\hline & $\mathbf{N}$ & $\begin{array}{l}\text { Hedonic intrinsic } \\
\text { motivation }\end{array}$ & $\begin{array}{l}\text { Extrinsic } \\
\text { motivation }\end{array}$ & $\begin{array}{c}\text { Normative intrinsic } \\
\text { motivation }\end{array}$ \\
\hline $\begin{array}{l}\text { Sharing knowledge is very } \\
\text { important for me. }\end{array}$ & 227 & .83 & .001 & .09 \\
\hline I like to share my knowledge. & 229 & .87 & .02 & -.007 \\
\hline $\begin{array}{l}\text { I feel good when I can help } \\
\text { someone with my knowledge. }\end{array}$ & 227 & .82 & -.09 & -.05 \\
\hline $\begin{array}{l}\text { Thanks to cooperation with others, } \\
\text { I learn and develop. }\end{array}$ & 225 & .83 & -.05 & -.04 \\
\hline $\begin{array}{l}\text { I share my knowledge because } \\
\text { I may obtain financial remuneration } \\
\text { for it from the company. }\end{array}$ & 228 & -.10 & .71 & .06 \\
\hline $\begin{array}{l}\text { I share my knowledge because } \\
\text { it means I can develop my career } \\
\text { in our company. }\end{array}$ & 227 & .007 & .87 & .01 \\
\hline $\begin{array}{l}\text { Sharing my knowledge enables } \\
\text { me to meet other people in the } \\
\text { organization. }\end{array}$ & 222 & .31 & .38 & -.26 \\
\hline $\begin{array}{l}\text { By sharing my knowledge, } \\
\text { I strengthen relations with people } \\
\text { in our organization. }\end{array}$ & 226 & .37 & .33 & -.30 \\
\hline $\begin{array}{l}\text { I share my knowledge because } \\
\text { I gain recognition and respect from } \\
\text { my colleagues. }\end{array}$ & 228 & .13 & .31 & -.31 \\
\hline $\begin{array}{l}\text { I share my knowledge because } \\
\text { it helps my company create new } \\
\text { business opportunities. }\end{array}$ & 225 & .03 & .17 & -.62 \\
\hline $\begin{array}{l}\text { I share my knowledge because } \\
\text { it helps my company improve } \\
\text { its work processes. }\end{array}$ & 225 & -.07 & -.09 & -1.01 \\
\hline $\begin{array}{l}\text { I share my knowledge because } \\
\text { it helps my company achieve } \\
\text { its performance objectives. }\end{array}$ & 227 & .05 & -.10 & -.83 \\
\hline Eigenvalues & & 5.64 & 1.92 & 1.02 \\
\hline$\%$ of variance & & 47.02 & 16.03 & 8.48 \\
\hline$\alpha$ & & .90 & .76 & .86 \\
\hline
\end{tabular}




\section{Business Administration and Management}

the factor loading after rotation. The items that cluster on the same factor suggest that factor 1 represents hedonic intrinsic motivation, factor 2 represents extrinsic, and factor 3 normative intrinsic motivation (see Tab. 1).

All subscales of the employees' motivation for knowledge sharing had good reliabilities (see Tab. 1). Similarly, the total scale has a high reliability too, Cronbach's $\alpha=.83$.
A summary of the basic statistical characteristics of the test scores is presented in Tab. 2. The means of indexes indicate that intrinsic motivation might be the main reason why employees share their knowledge in the organization. This supports the claim of Osterloh and Frey (2000 as cited in Ardichvili et al., 2003), who believe that intrinsic motives are much more powerful enablers of knowledge

\section{Tab. 2: Basic statistical characteristics of the tests employed in the survey}

\begin{tabular}{l|c|c|c|c|c} 
& $\mathbf{N}$ & Mean & $\begin{array}{c}\text { Std. } \\
\text { Deviation }\end{array}$ & Minimum & Maximum \\
\hline Index of knowledge sharing & 315 & .626 & .136 & .227 & 1.000 \\
\hline $\begin{array}{l}\text { Index of total motivation for knowledge } \\
\text { sharing }\end{array}$ & 229 & .729 & .134 & .311 & 1.000 \\
\hline $\begin{array}{l}\text { Index of hedonic intrinsic motivation } \\
\text { for knowledge sharing }\end{array}$ & 229 & .849 & .150 & .200 & 1.000 \\
\hline $\begin{array}{l}\text { Index of extrinsic motivation for } \\
\text { knowledge sharing }\end{array}$ & 229 & .492 & .227 & .200 & 1.000 \\
\hline $\begin{array}{l}\text { Index of normative intrinsic motivation } \\
\text { for knowledge sharing }\end{array}$ & 228 & .728 & .190 & .200 & 1.000 \\
\hline
\end{tabular}

and sample sizes

\begin{tabular}{|c|c|c|c|c|c|}
\hline & 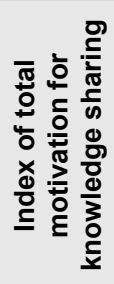 & 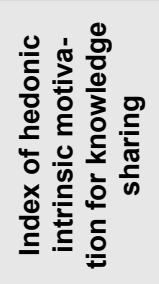 & 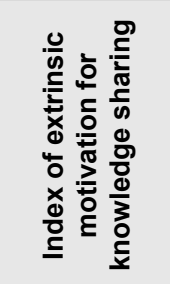 & 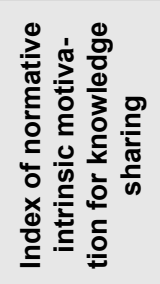 & 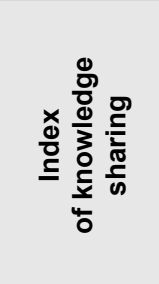 \\
\hline $\begin{array}{l}\text { Index of total motivation for } \\
\text { knowledge sharing }\end{array}$ & 1 & $\begin{array}{c}.784^{* \star *} \\
{[.722, .832]}\end{array}$ & $\begin{array}{c}.532^{\star * *} \\
{[.409, .632]}\end{array}$ & $\begin{array}{c}.853^{\star \star *} \\
{[.818, .885]}\end{array}$ & $\begin{array}{c}.459^{* * *} \\
{[.220, .642]}\end{array}$ \\
\hline $\begin{array}{l}\text { Index of hedonic intrinsic } \\
\text { motivation for knowledge } \\
\text { sharing }\end{array}$ & 228 & 1 & $\begin{array}{c}.061 \\
{[-.098, .194]}\end{array}$ & $\begin{array}{c}.554^{* * *} \\
{[.443, .652]}\end{array}$ & $\begin{array}{c}.246^{*} \\
{[-.019, .491]}\end{array}$ \\
\hline $\begin{array}{l}\text { Index of extrinsic motivation } \\
\text { for knowledge sharing }\end{array}$ & 228 & 228 & 1 & $\begin{array}{c}.259^{\star \star *} \\
{[.111, .390]}\end{array}$ & $\begin{array}{c}.263^{* *} \\
{[.050, .444]}\end{array}$ \\
\hline $\begin{array}{l}\text { Index of normative intrinsic } \\
\text { motivation for knowledge } \\
\text { sharing }\end{array}$ & 228 & 228 & 228 & 1 & $\begin{array}{c}.544^{\star \star \star} \\
{[.316, .708]}\end{array}$ \\
\hline Index of knowledge sharing & 96 & 99 & 99 & 99 & 1 \\
\hline
\end{tabular}

Source: own Notes: ${ }^{*} p<.05,{ }^{* *} p<.01,{ }^{* * *} p<.001$. Bias corrected and accelerated bootstrap $95 \%$ Cls are reported in square brackets. 
sharing than are extrinsic stimuli. Additionally, the results indicate that participants share knowledge mainly because they find it to be an enjoyable, self-determined, and competenceenhancing activity.

The Pearson's correlation coefficient method was used to examine the correlation between the employees' motivation for knowledge sharing (and its subscales) and perceived knowledge sharing in the organization (see Tab. 3).

Four hypotheses were examined with the following results:

H1: There is a positive statistically significant correlation between employee motivation for knowledge sharing and knowledge sharing in the organization. This hypothesis was supported, because employee motivation to knowledge sharing was significantly related to the intensity of knowledge sharing in the organization, $r=.459,95 \% \mathrm{BCa} \mathrm{Cl}[.220, .642]$, $p<.001$. The identified relationship between knowledge sharing and employee motivation is in accordance with previous studies.

H2: There is a positive statistically significant correlation between employee hedonic intrinsic motivation for knowledge sharing and knowledge sharing in the organization. This hypothesis was supported, but the correlation was only weak, $r=.246,95 \%$ $\mathrm{BCa} \mathrm{Cl}[-.019, .491], p=.014$

H3: There is a positive statistically significant correlation between employee normative intrinsic motivation for knowledge sharing and knowledge sharing in the organization. This hypothesis was supported and the correlation was moderate, $r=.544,95 \% \mathrm{BCa}$ $\mathrm{Cl}[.316, .708], p<.001$. It is interesting that normative intrinsic motivation has a bigger influence on knowledge sharing than hedonic intrinsic motivation. There are several possible explanations why normative intrinsic motivation has a greater correlation with knowledge sharing than hedonic. For example, it could be because of the size of the sample (the sample used for correlation analysis was smaller than for basic statistical analysis), or it might be an impact of response bias (e.g. a difference is known between what people say they do and what they really do).

H4: There is a positive statistically significant correlation between employee extrinsic motivation for knowledge sharing and knowledge sharing in the organization.
This hypothesis was supported, but the correlation was only weak, $r=.263,95 \% \mathrm{BCa}$ $\mathrm{Cl}[.050, .444], p=.009$. Based on experience related to the research project, it is possible that Czech organizations simply do not realize the importance of knowledge sharing and they do not try to influence the intensity of knowledge sharing by some adjustment in performance management, rewards, career advancement and so on.

Additionally, statistically significant positive correlations were found among motivation subscales with one exception. Surprisingly, no significant correlation was found between hedonic intrinsic motivation and extrinsic motivation, $r=.061,95 \% \mathrm{BCa} \mathrm{Cl}[-.098, .194]$, $p=.36$. This could be interpreted as indicating that whether an employee gets an additional reward (in a broader sense of meaning) or not does not have an influence on how he/she perceives the task and its context, i.e. a boring task will be still boring regardless of whether hel she gets an extra remuneration. This supports some doubts about the efficiency of extrinsic (especially monetary) rewards used to enhance employee motivation - see e.g. Pink (2011).

\section{Conclusions}

The goal of this study was to examine employee motivation for knowledge sharing and to find out which kind of motivation is essential to knowledge sharing. Firstly, Gottschalg and Zollo's (2007) subtypes of motivation (extrinsic, hedonic intrinsic, and normative intrinsic) were confirmed by a principal axis factor analysis. The final inventory of employee motivation to knowledge sharing had a high reliability too. Therefore, the inventory could be used in future research.

The study findings signify that intrinsic motivation is the main reason why employees share their knowledge in the organization. Initially, hedonic intrinsic motivation seemed to be the main driver (based on the questionnaire of motivation for knowledge sharing). However, a correlation analysis between motivation to knowledge sharing and the intensity of knowledge sharing was done and the results offer a different conclusion. In accordance with expectations, motivation for knowledge sharing and all their subtypes were significantly related to knowledge sharing. All of these correlations were positive, and in the case of normative intrinsic motivation the correlation was 
moderate. The results of the correlation analysis indicate that the core driver of knowledge sharing (from the types of motivation) could be rather normative intrinsic motivation than hedonic intrinsic motivation.

The findings might imply to the managers that it is appropriate to support employee organizational commitment and achieve in this way higher employee normative intrinsic motivation. Tactics used to this aim are for example: team building (Collins \& Smith, 2006), employee participation in decision making (Chen \& Huang, 2009; López, Peón, \& Ordás, 2006), fairness of rewards (Cabrera \& Cabrera, 2005), and employee selection practices that focus on creating internal labor markets (Collins \& Smith, 2006). Additionally, cultural norms and values are other organizational attributes that play an important role in affecting organizational commitment (Gottschalg \& Zollo, 2007).

As other types of motivation to knowledge sharing correlate with the intensity of knowledge sharing too, it might be appropriate to support them as well. Since hedonic intrinsic motivation is related to the perceived characteristics of the task and the task context (Gottschalg \& Zollo, 2007), managers should encourage such perception of knowledge sharing among employees and increase the level of enjoyment that employees experience as they help one another through knowledge sharing as Lin (2007) points out. This might be done, for example, by offering enough time and opportunities for informal knowledge sharing. Another possibility is work setting adjustment, like installing a coffee machine or kitchen where people have a tendency to meet and share knowledge as for example Mládková (2008) mentions. In the case of extrinsic motivation, common incentives include monetary rewards, recognition, promotion, and job security (Lee \& Ahn, 2007; Lin, 2007), which should be offered to employee if they share their knowledge.

The study enhances the understanding of the relationship between employee motivation and knowledge sharing as well as of relationships among subtypes of motivation. In sum, the answer to the initial research question might be simple: Regarding knowledge sharing, all kinds of motivation matter in the Czech Republic. However, employee normative intrinsic motivation is probably the main motivation-driver to knowledge sharing. Future research could focus more on the ways in which organizations try to influence employee motivation for knowledge sharing.

\section{Limitations of the Study}

Several important limitations of this study must be noted. The study was done on a particular sample of employees in a particular setting. Predominantly employees from the manufacturing, construction, and educational sectors took part in the survey. Additionally, the testing was voluntary, which can influence the representativeness of the sample. Furthermore, only a relatively small group of employees (102) completed both questionnaires and we were able to award both questionnaires to the same participant. Additionally, the data were self-reported and such data are prone to errors of memory and response bias due to social desirability. Therefore, the findings should not be over-generalized.

This contribution was written with the support of the internal TBU project RO/2016/07, "The improvement of organizations' performance through human capital management."

\section{References}

Anwar, C. M. (2017). Linkages between personality nad knowledge sharing behavior in workplace: mediating role of affective states. E\&M Ekonomie a Management, 20(2), 102-115. https://doi.org/10.15240/tul/001/2017-2-008.

Ardichvili, A., Page, V., \& Wentling, T. (2003). Motivation and barriers to participation in virtual knowledge-sharing communities of practice. Journal of Knowledge Management, 7(1), 64-77. https://doi.org/10.1108/13673270310463626.

Barbuto, J. E., \& Scholl, R. W. (1998). Motivation Sources Inventory: Development and Validation of New Scales to Measure an Integrative Taxonomy of Motivation. Psychological Reports, 82(3), 1011-1022. https://doi.org/10.2466/pr0.1998.82.3.1011.

Bock, G.-W., Zmud, R. W., Kim, Y.-G., \& Lee, J.-N. (2005). Behavioral intention formation in knowledge sharing: Examining the roles of extrinsic motivators, socialpsychological forces, and organizational climate. MIS Quarterly, 29(1), 87-111. https://doi.org/10.2307/25148669.

Bose, R. (2004). Knowledge management metrics. Industrial Management \& Data Systems, 104(6), 457-468. https://doi. org/10.1108/02635570410543771. 
Cabrera, Á., Collins, W. C., \& Salgado, J. F. (2006). Determinants of individual engagement in knowledge sharing. The International Journal of Human Resource Management, 17(2), 245-264. https://doi. org/10.1080/09585190500404614.

Cabrera, E. F., \& Cabrera, A. (2005). Fostering knowledge sharing through people management practices. International Journal of Human Resource Management, 16(5), 720-735. https://doi.org/10.1080/09585190500083020.

Chen, C.-J., \& Huang, J.-W. (2009). Strategic human resource practices and innovation performance - The mediating role of knowledge management capacity. Journal of Business Research, 62(1), 104-114. https://doi. org/10.1016/j.jbusres.2007.11.016.

Chen, S.-S., Chuang, Y.-W., \& Chen, P.-Y. (2012). Behavioral intention formation in knowledge sharing: Examining the roles of KMS quality, KMS self-efficacy, and organizational climate. Knowledge-Based Systems, 31, 106-118. https://doi.org/10.1016/j.knosys.2012.02.001.

Chow, C. W., Deng, F. J., \& Ho, J. L. (2000). The openness of knowledge sharing within organizations: A comparative study in the United States and the People's Republic of China. Journal of Management Accounting Research, 12(1), 65-95. https://doi.org/10.2308/ jmar.2000.12.1.65.

Collins, C. J., \& Smith, K. G. (2006). Knowledge exchange and combination: The role of human resource practices in the performance of high-technology firms. Academy of Management Journal, 49(3), 544-560. https://doi.org/10.5465/amj.2006.21794671.

Deci, E. L., \& Ryan, R. M. (2000). The 'What' and 'Why' of Goal Pursuits: Human Needs and the Self-Determination of Behavior. Psychological Inquiry, 11(4), 227-268. https://doi.org/10.1207/S15327965PLI1104_01.

Donate, M. J., \& Guadamillas, F. (2011). Organizational factors to support knowledge management and innovation. Journal of Knowledge Management, 15(6), 890-914. https://doi.org/10.1108/13673271111179271.

Field, A. P. (2013). Discovering statistics using IBM SPSS statistics: and sex and drugs and rock ' $n$ ' roll (4th ed.). Los Angeles: Sage.

Fong, C., Ooi, K., Tan, B., Lee, V., \& Chong, A. Y. (2011). HRM practices and knowledge sharing: an empirical study. International Journal of Manpower, 32(5/6), 704-723. https://doi.org/10.1108/01437721111158288.
Foss, N. J., Pedersen, T., Reinholt Fosgaard, M., \& Stea, D. (2015). Why Complementary HRM Practices Impact Performance: The Case of Rewards, Job Design, and Work Climate in a Knowledge-Sharing Context. Human Resource Management, 54(6), 955-976. https://doi. org/10.1002/hrm.21649.

Gottschalg, O., \& Zollo, M. (2007). Interest alignment and competitive advantage. Academy of Management Review, 32(2), 418-437. https://doi.org/10.5465/amr.2007.24351356.

Haas, M. R., \& Hansen, M. T. (2007). Different knowledge, different benefits: toward a productivity perspective on knowledge sharing in organizations. Strategic Management Journal, 28(11), 1133-1153. https://doi.org/10.1002/smj.631.

Hau, Y. S., Kim, B., Lee, H., \& Kim, Y.-G. (2013). The effects of individual motivations and social capital on employees' tacit and explicit knowledge sharing intentions. International Journal of Information Management, 33(2), 356-366. https://doi.org/10.1016/j. ijinfomgt.2012.10.009.

Hooff, B. van den, \& Ridder, J. A. de. (2004). Knowledge sharing in context: the influence of organizational commitment, communication climate and CMC use on knowledge sharing. Journal of Knowledge Management, 8(6), 117-130. https://doi. org/10.1108/13673270410567675.

Husted, K., \& Michailova, S. (2002). Diagnosing and Fighting Knowledge-Sharing Hostility. Organizational Dynamics, 31(1), 60-73. https://doi.org/10.1016/S0090-2616(02)00072-4.

Hutcheson, G., \& Sofroniou, N. (1999). The multivariate social scientist: introductory statistics using generalized linear models. London; Thousand Oaks, Calif: Sage Publications.

Ipe, M. (2003). Knowledge Sharing on Organizations:AConceptual Framework. Human Resource Development Review, 2(4), 337-359. https://doi.org/10.1177/1534484303257985.

Kazdová, A. (2012). O motivovanosti ve firmách rozhodují sdílené hodnoty. HRM: Human Resource Management, 8(3). Retrieved from http://hrm.inned.cz/c1-55942340o-motivovanosti-ve-firmach-rozhoduji-sdilenehodnoty.

Law, C. C., \& Ngai, E. W. (2008). An empirical study of the effects of knowledge sharing and learning behaviors on firm performance. Expert Systems with Applications, 34(4), 2342-349. https://doi.org/10.1016/j.eswa.2007.03.004. 
Lee, D.-J., \& Ahn, J.-H. (2007). Reward systems for intra-organizational knowledge sharing. European Journal of Operational Research, 180(2), 938-956. https://doi. org/10.1016/j.ejor.2006.03.052.

Li-An, H., \& Kuo, T.-H. (2013). How system quality and incentive affect knowledge sharing. Industrial Management + Data Systems, 113(7), 1048-1063. https://doi.org/10.1108/IMDS-012013-0015.

Lin, C.-P. (2007). To Share or Not to Share: Modeling Tacit Knowledge Sharing, Its Mediators and Antecedents. Journal of Business Ethics, 70(4), 411-428. https://doi. org/10.1007/s10551-006-9119-0.

Lin, H., \& Lee, G. (2004). Perceptions of senior managers toward knowledge-sharing behaviour. Management Decision, 42(1), 108-125. https:// doi.org/10.1108/00251740410510181.

Lin, H.-F. (2007). Effects of extrinsic and intrinsic motivation on employee knowledge sharing intentions. Journal of Information Science, 33(2), 135-149. https://doi. org/10.1177/0165551506068174.

López, S. P., Peón, J. M. M., \& Ordás, C. J. V. (2006). Human Resource Management as a Determining Factor in Organizational Learning. Management Learning, 37(2), 215-239. https:// doi.org/10.1177/1350507606063443.

Matošková, J. (2016). Measuring Knowledge. Journal of Competitiveness, 8(4), 5-29. https://doi.org/10.7441/joc.2016.04.01.

Matošková, J., Řeháčková, H., Sobotková, E., Polčáková, M., Jurásek, M., Gregar, A., \& Švec, V. (2013). Facilitating Leader Tacit Knowledge Acquisition. Journal of Competitiveness, 5(1), 3-13. https://doi.org/10.7441/joc.2013.01.01.

Mládková, L. (2008). Management znalostních pracovníkù. Prague: C.H. Beck.

Peet, M. (2012). Leadership transitions, tacit knowledge sharing and organizational generativity. Journal of Knowledge Management, 16(1), 4560. https://doi.org/10.1108/13673271211198936.

Pink, D. H. (2011). Pohon: prekvapivá pravda o tom, co nás motivuje! Olomouc: ANAG.

Quigley, N. R., Tesluk, P. E., Locke, E. A., \& Bartol, K. M. (2007). A Multilevel Investigation of the Motivational Mechanisms Underlying Knowledge Sharing and Performance. Organization Science, 18(1), 71-88. https://doi. org/10.1287/orsc.1060.0223.

Riege, A. (2005). Three-dozen knowledgesharing barriers managers must consider. Journal of Knowledge Management, 9(3), 18-35. https://doi.org/10.1108/13673270510602746.

Sandhu, M. S., Jain, K. K., \& Ahmad, I. U. K. bte. (2011). Knowledge sharing among public sector employees: evidence from Malaysia. The International Journal of Public Sector Management, 24(3), 206-226. https://doi. org/10.1108/09513551111121347.

Seba, I., Rowley, J., \& Lambert, S. (2012). Factors affecting attitudes and intentions towards knowledge sharing in the Dubai Police Force. International Journal of Information Management, 32(4), 372-380. https://doi. org/10.1016/j.jinfomgt.2011.12.003.

Singh, S. K. (2008). Role of leadership in knowledge management: a study. Journal of Knowledge Management, 12(4), 3-15. https://doi.org/10.1108/13673270810884219.

Swift, M., Balkin, D. B., \& Matusik, S. F. (2010). Goal orientations and the motivation to share knowledge. Journal of Knowledge Management, 14(3), 378-393. https://doi. org/10.1108/13673271011050111.

Tuan, L. T. (2012). Behind knowledge transfer. Management Decision, 50(3), 459-478. https://doi.org/10.1108/00251741211216232.

Urbancová, H. (2012). The Process of Knowledge Continuity Ensuring. Journal of Competitiveness, 4(2), 38-48. https://doi. org/10.7441/joc.2012.02.03.

Wong, K. Y. (2005). Critical success factors for implementing knowledge management in small and medium enterprises. Industrial Management \& Data Systems, 105(3), 261-279. https://doi.org/10.1108/02635570510590101.

Yen-Ku Kuo, Tsung-Hsien Kuo, \& Li-An Ho. (2014). Enabling innovative ability: knowledge sharing as a mediator. Industrial Management \& Data Systems, 114(5), 696-710. https://doi. org/10.1108/IMDS-10-2013-0434.

Zaqout, F., \& Abbas, M. (2012). Towards a model for understanding the influence of the factors that stimulate university students' engagement and performance in knowledge sharing. Library Review, 61(5), 345-361. https://doi.org/10.1108/00242531211280478.

Ing. Jana Matošková, Ph.D. Tomas Bata University in Zlín Faculty of Management and Economics Department of Management and Marketing Czech Republic matoskova@fame.utb.cz 


\section{Appendix 1: Knowledge sharing inventory}

1. A typical employee of our company contributes through ideas and inspiration to the knowledge archive of the company, e.g. the company knowledge database.

2. A typical employee in our company is involved in the documentation of important knowledge, e.g. elaborates instructions from the project, knowledge about clients.

3. Proposals are collected in the company from other employees, clients, partners and vendors and are used during decisions.

4. Employees are informed of the turnover, revenue, economic and strategic issues in the company.

5. A typical employee in our company does not express his/her ideas and inspirations.

6. A typical employee in our company provides others with feedback.

7. A typical employee in our company helps others to manage the knowledge and skills needed for their work.

8. During decisions, e.g. about investment into company, the proposals of employees are taken into consideration.

9. A typical employee in our company shares knowledge acquired from education or a development programme with other members of the organisation.

10. A typical employee in our company regularly participates in seminars and workshops to share knowledge and learn from others.

11. A typical employee in our company shares stories of success and procedures that are well established.

12. Communication in our company is bilateral (i.e. from the supervisor to subordinates, and vice versa).

13. A typical employee in our company communicates his/her most recent work related errors and mistakes, as well as procedures that were not well established in order to prevent others from making the same mistakes and errors.

14. Each team regularly meets and resolves problems and reviews the options and opportunities in its area.

15. A standard part of the work of employees is to pass on information, e.g. within meetings. 


\section{Abstract}

\section{WHY EMPLOYEES SHARE THEIR KNOWLEDGE}

\section{Jana Matošková}

Sharing knowledge among employees reduces the risk of losing unique knowledge, contributes to higher productivity and to higher quality, to better problem-solving, to reducing costs, and to organizational innovativeness. Knowledge sharing is driven by employee motivation for it. Nevertheless, motivation is not a simple construct. Therefore, the goal of this study was to find out which kind of motivation is essential to knowledge sharing. An inventory taking into account three types of motivation (hedonic intrinsic, normative intrinsic, and extrinsic) was constructed and a principal axis factor analysis was done. 229 participants from nine organizations fulfilled the questionnaire aimed at their motivation to knowledge sharing. The factor analysis confirmed the questionnaire construction and the inventory demonstrates a high reliability. Based on the mean of the indexes that were calculated, hedonic intrinsic motivation seemed to be the main driver of knowledge sharing. However, the relationship between motivation for knowledge sharing and the intensity of knowledge sharing in the organization was examined as well $(N=99)$. Motivation for knowledge sharing and all its factors were identified to be significantly related to knowledge sharing. All of these correlations were positive, and in the case of normative intrinsic motivation the correlation was moderate. That is why rather normative intrinsic motivation (and not hedonic intrinsic motivation) is essential. Additionally, the results showed no significant correlation between hedonic intrinsic motivation and extrinsic motivation. The study indicates that managers in the Czech Republic should support employee organizational commitment if they want to achieve a higher intensity of knowledge sharing.

Key Words: Knowledge sharing, intrinsic motivation, extrinsic motivation, organization.

JEL Classification: M12.

DOI: 10.15240/tul/001/2019-2-006 